\title{
THE
}

\section{Untangling Intra- and Interspecific Effects on Body Size Clines Reveals Divergent Processes Structuring Convergent Patterns in Anolis Lizards}

Martha M. Muñoz

Johanna E. Wegener

University of Rhode Island

Adam C. Algar

Follow this and additional works at: https://digitalcommons.uri.edu/bio_facpubs

Terms of Use

All rights reserved under copyright.

\section{Citation/Publisher Attribution}

Martha M. Muñoz, Johanna E. Wegener, and Adam C. Algar, "Untangling Intra- and Interspecific Effects on Body Size Clines Reveals Divergent Processes Structuring Convergent Patterns in Anolis Lizards.," The American Naturalist 184, no. 5 (November 2014): 636-646.

Available at: https://doi.org/10.1086/678084

This Article is brought to you for free and open access by the Biological Sciences at DigitalCommons@URI. It has been accepted for inclusion in Biological Sciences Faculty Publications by an authorized administrator of DigitalCommons@URI. For more information, please contact digitalcommons-group@uri.edu. 


\section{CHICAGO JOURNALS}

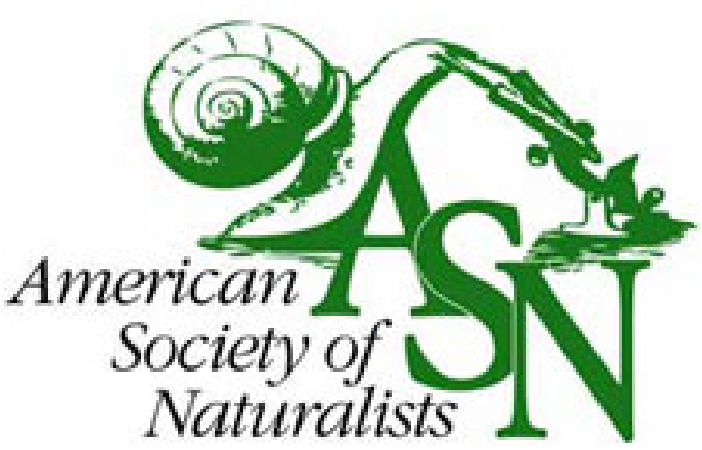

The University of Chicago

Untangling Intra- and Interspecific Effects on Body Size Clines Reveals Divergent Processes Structuring Convergent Patterns in Anolis Lizards.

Author(s): Martha M. Muñoz, Johanna E. Wegener, and Adam C. Algar

Source: The American Naturalist, Vol. 184, No. 5 (November 2014), pp. 636-646

Published by: The University of Chicago Press for The American Society of Naturalists

Stable URL: http://www.jstor.org/stable/10.1086/678084

Accessed: 09/09/2015 09:00

Your use of the JSTOR archive indicates your acceptance of the Terms \& Conditions of Use, available at http://www.jstor.org/page/info/about/policies/terms.jsp

JSTOR is a not-for-profit service that helps scholars, researchers, and students discover, use, and build upon a wide range of content in a trusted digital archive. We use information technology and tools to increase productivity and facilitate new forms of scholarship. For more information about JSTOR, please contact support@jstor.org. 


\title{
Untangling Intra- and Interspecific Effects on Body Size Clines Reveals Divergent Processes Structuring Convergent Patterns in Anolis Lizards
}

\author{
Martha M. Muñoz, ${ }^{1, \star}$ Johanna E. Wegener, ${ }^{2}$ and Adam C. Algar ${ }^{3}$ \\ 1. Department of Organismic and Evolutionary Biology, Harvard University, Cambridge, Massachusetts 02138; 2. Department of \\ Biological Sciences, University of Rhode Island, Kingston, Rhode Island 02881; 3. School of Geography, University of Nottingham, \\ Nottingham NG7 2RD, United Kingdom \\ Submitted January 13, 2014; Accepted July 8, 2014; Electronically published October 1, 2014 \\ Online enhancement: appendix. Dryad data: http://dx.doi.org/10.5061/dryad.q39h2.
}

\begin{abstract}
Bergmann's rule-the tendency for body size to increase in colder environments-remains controversial today, despite 150 years of research. Considerable debate has revolved around whether the rule applies within or among species. However, this debate has generally not considered that clade-level relationships are caused by both intra- and interspecific effects. In this article, we implement a novel approach that allows for the separation of intra- and interspecific components of trait-environment relationships. We apply this approach to body size clines in two Caribbean clades of Anolis lizards and discover that their similar body size gradients are constructed in very different ways. We find inverse Bergmann's clines-highelevation lizards are smaller bodied — for both the cybotes clade on Hispaniola and the sagrei clade on Cuba. However, on Hispaniola, the inverse cline is driven by interspecific differences, whereas intraspecific variation is responsible for the inverse cline on Cuba. Our results suggest that similar body size clines can be constructed through differing evolutionary and ecological processes, namely, through local adaptation or phenotypic plasticity (intraspecific clines) and/or size-ordered spatial sorting (interspecific clines). We propose that our approach can help integrate a divided research program by focusing on how the combined effects of intra- and interspecific processes can enhance or erode clade-level relationships at large biogeographic scales.
\end{abstract}

Keywords: Bergmann's rule, Anolis lizards, body size clines, sizeordered species turnover.

\section{Introduction}

Large-scale patterns in trait variation that we see today are a major source of phenotypic diversity (Mayr 1956; Blackburn et al. 1999; Ackerly and Cornwell 2007; Lepš et al. 2011; Meiri 2011). Spatial variation in body size is one such pervasive pattern. In particular, body size is known

\footnotetext{
* Corresponding author; e-mail: martha.munoz@gmail.com.
}

Am. Nat. 2014. Vol. 184, pp. 636-646. (C) 2014 by The University of Chicago. 0003-0147/2014/18405-55210\$15.00. All rights reserved. DOI: $10.1086 / 678084$ to vary across thermal environments, such that it may increase (Bergmann's cline), decrease (inverse Bergmann's cline), or vary little with elevation and/or latitude (Ashton and Feldman 2003; Pincheira-Donoso et al. 2008). Bergmann's rule (sensu stricto) was initially proposed to explain the tendency for endothermic organisms in colder climates to be larger bodied. The pattern was described as an interspecific cline manifested in homeothermic animals (Bergmann 1847; James 1970); the proposed mechanism underlying this pattern was the conservation of heat through a smaller surface area-to-volume ratio in largerbodied animals. More recently, however, the rule (sensu lato) has been extended to include intraspecific size clines and ectothermic organisms, especially squamates (Rensch 1938; Ashton and Feldman 2003; de Queiroz and Ashton 2004; Olalla-Tárraga et al. 2006) and insects (Chown and Gaston 2010; Shelomi 2012). As empirical studies accumulated, new interpretations of the mechanisms underlying Bergmann's cline emerged. These interpretations involve environmental factors correlated with temperature or differences in thermoregulatory ability (reviewed in Meiri 2011; Olalla-Tárraga 2011).

Despite various empirical and theoretical developments, it remains challenging to bridge studies conducted at different phylogenetic scales. Much debate surrounding Bergmann's rule has focused on whether it should occur within or among species (Mayr 1956; Blackburn et al. 1999; Meiri 2011), largely considering intra- and interspecific body size clines separately. However, at the clade level, clines of body size (or any other trait) reflect intra- and interspecific variation. Within species, body size-environment relationships, like other trait-environment correlations, can arise because of local adaptation and/or phenotypic plasticity (Phillimore et al. 2010, 2012). However, differences in mean body size among species (beyond the effects of local adaptation and plasticity) may also contribute to body size 
clines because of evolutionary divergence and size-structured species turnover, such that larger species replace smaller ones along an environmental gradient (Blackburn et al. 1999; Meiri and Thomas 2007). Finally, species-specific differences in local adaptation and plasticity may strengthen or weaken these effects. Thus, factors operating both within and among species may enhance or degrade clade-level clinal relationships.

In this article, we take an integrative approach by simultaneously considering intra- and interspecific contributions to body size clines. At the interspecific level, we focus on cross-taxon comparisons rather than assemblagebased approaches (sensu Olalla-Tárraga 2011). Specifically, we formulate and test eight competing hypotheses ( $\mathrm{H} 1-$ $\mathrm{H} 8$ below; fig. 1; table 1) for how intra- and interspecific factors can interact to construct body size clines along elevation gradients. Body size clines may be solely explained by local adaptation and plasticity, with no additional interspecific contributions, leading to a single overall cline (H1). Alternatively, either interspecific divergence or local adaptation and plasticity may be the only source of variation, resulting in purely interspecific (H2) or intraspecific clines (H3). When body size clines are due to a mixture of intra- and interspecific effects, they may be concordant (H4) or discordant (H5). In addition, there may be varying intraspecific clines, either with an interspecific cline (H6) or without (H7). Finally, there may be no intra- or interspecific clines whatsoever ( $\mathrm{H} 8)$.

We test these eight hypotheses by using two clades of Caribbean Anolis lizards from Cuba and Hispaniola as model systems. Divergence in body size is an important feature of the adaptive radiation of Greater Antillean Anolis lizards (Williams 1983; Losos 2009). For this study, we focus on body size divergence within two deeply divergent clades from Cuba and Hispaniola. On these islands, lizards are found in environments ranging from scrubby semidesert to montane pine forests, which pose different selective pressures (Glor et al. 2003; Muñoz et al. 2014a) and provide the opportunity for body size adaptation. By comparing the intra- and interspecific contributions to body size on both of these islands, we test whether size clines are replicated across independent but ecologically convergent clades of Anolis lizards in similar thermal environments.

\section{Methods}

\section{Data Collection}

We assembled body size data of 16 Anolis species from the cybotes (seven species) and sagrei (nine species) clades in Hispaniola and Cuba, respectively. Anoles from both clades are found in nearly all the available habitats on their islands (Henderson and Powell 2009). Further, the two clades are similar in that they include a mix of widespread (e.g., $A$.

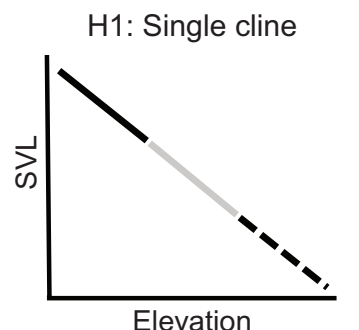

H2: Interspecific cline only

H3: Intraspecific clines only

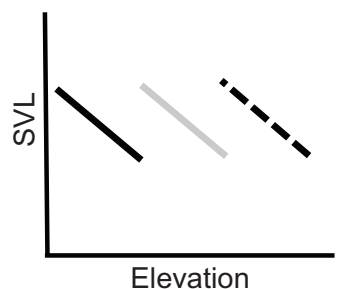

$\mathrm{H} 4$ : Consistent intraspecific and interspecific clines

H5: Contrasting intraspecific and interspecific clines
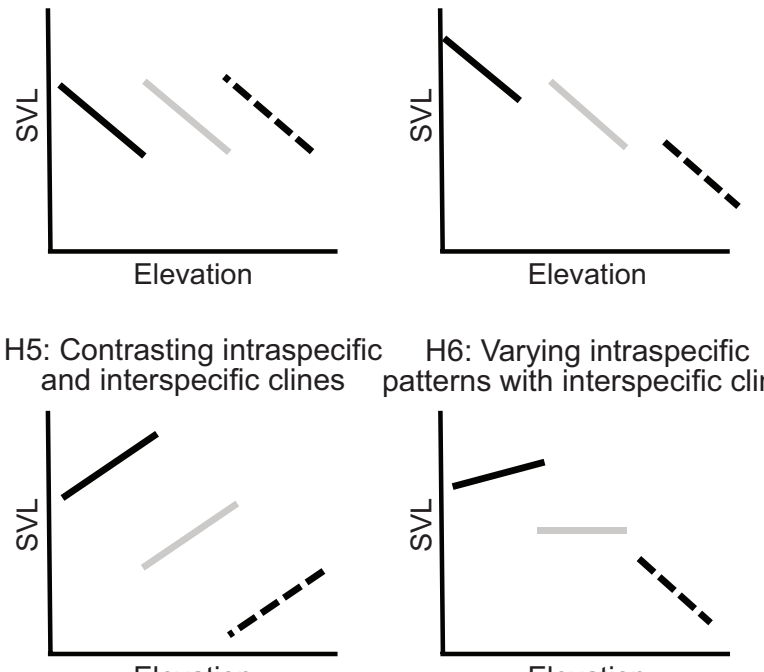

Elevation

H6: Varying intraspecific patterns with interspecific cline

$\mathrm{H7}$ : Varying intraspecific patterns; no interspecific cline

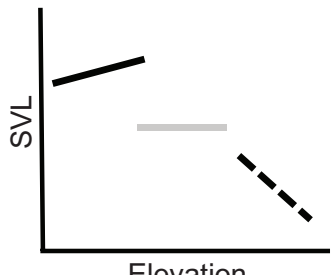

Elevation

H8: No clines

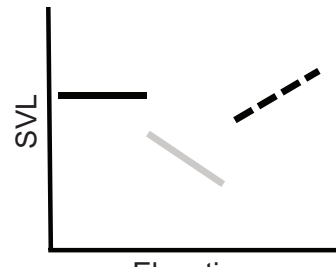

Elevation

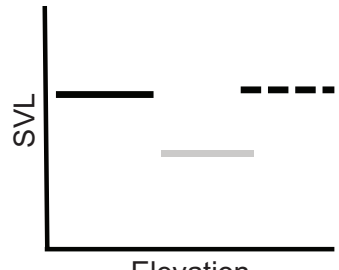

Elevation

Figure 1: The eight hypotheses for the construction of body size clines along elevational gradients from intra- and interspecific clines. In each plot, three hypothetical species (represented by solid black, solid gray, and dashed lines) are shown. Inverse Bergmann's clines are depicted (decreasing size with increasing elevation), as these are often observed in squamates, but the hypotheses apply identically to positive Bergmann's clines. SVL $=$ snout-vent length.

cybotes on Hispaniola and A. sagrei on Cuba) and rangerestricted (e.g., A. shrevei on Hispaniola and A. rubribarbus on Cuba; Glor et al. 2003; Knouft et al. 2006) species, suggesting that differences in species delimitation between clades is unlikely to bias our results. We measured body size from ethanol-preserved specimens in the herpetological collection at the Museum of Comparative Zoology at Harvard 
Table 1: Predictions of the eight hypotheses for the construction of body size clines along elevational gradients

\begin{tabular}{|c|c|}
\hline Hypothesis & Predictions \\
\hline \multirow[t]{3}{*}{$\mathrm{H} 1$} & 1. Significant SVL-elevation slope (model 1) \\
\hline & 2. No difference in intercepts after elevation is accounted for (model 3 vs. model 1 ) \\
\hline & 3. No slope differences among species (model 4 vs. model 3) \\
\hline \multirow[t]{3}{*}{$\mathrm{H} 2$} & 1. Significant difference in species means (model 2) \\
\hline & 2. No significant individual SVL-elevation slopes (individual species regressions) \\
\hline & 3. Significant relationship between mean SVL and mean elevation (model 5) \\
\hline \multirow[t]{4}{*}{$\mathrm{H} 3$} & 1. No differences in species means (model 2 ) \\
\hline & 2. Significant slope after intercept differences are accounted for (model 3 vs. model 2) \\
\hline & 3. No slope differences among species (model 4 vs. model 3) \\
\hline & 4. All individual SVL-elevation slopes significant in same direction (individual species regressions) \\
\hline \multirow[t]{5}{*}{$\mathrm{H} 4$} & 1. Significant intercept differences after elevation is accounted for (model 3 vs. model 1) \\
\hline & 2. Significant slope after intercept differences are accounted for (model 3 vs. model 2) \\
\hline & 3. No slope differences among species (model 4 vs. model 3) \\
\hline & 4. All individual SVL-elevation slopes significant in same direction (individual species regressions) \\
\hline & 5. Significant relationship between mean SVL and mean elevation (model 5) \\
\hline \multirow[t]{5}{*}{ H5 } & 1. Significant intercept differences after elevation is accounted for (model 3 vs. model 1 ) \\
\hline & 2. No slope differences among species (model 4 vs. model 3) \\
\hline & 3. All individual SVL-elevation slopes significant in same direction (individual species regressions) \\
\hline & 4. Significant relationship between mean SVL and mean elevation (model 5) \\
\hline & $\begin{array}{l}\text { 5. Directions of mean SVL-elevation and individual SVL-elevation slopes differ (individual species regressions } \\
\text { and model 5) }\end{array}$ \\
\hline \multirow[t]{3}{*}{ H6 } & 1. Significant difference in species means (model 2) \\
\hline & 2. Significant relationship between mean SVL and mean elevation (model 5) \\
\hline & 3. Significant slope differences among species (model 4 vs. model 3) \\
\hline \multirow[t]{3}{*}{$\mathrm{H} 7$} & 1. Significant slope differences among species (model 4 vs. model 3 ) \\
\hline & 2. No relationship between mean SVL and mean elevation (model 5) \\
\hline & 3. At least one individual species' SVL-elevation slope is significant (individual species regressions) \\
\hline \multirow[t]{3}{*}{$\mathrm{H} 8$} & 1. No relationship between SVL and elevation (model 1) \\
\hline & 2. No relationship between mean SVL and mean elevation (model 5) \\
\hline & 3. No significant individual SVL-elevation slopes (individual species regressions) \\
\hline
\end{tabular}

\footnotetext{
Note: The linear models used to test each prediction are indicated in parentheses. Model 1 is a linear regression of snout-vent length (SVL) on elevation, pooling all species. Model 2 is a one-way ANOVA to test for mean body size differences among species. Model 3 is an ANCOVA that constrains SVLelevation slopes to be identical but allows intercepts to vary. Model 4 is an ANCOVA with an interaction term that allows both slopes and intercepts to vary. Model 5 is the regression of species' mean SVL on species' mean elevation.
}

University, ensuring a minimum of five individuals from at least two localities for each species (table A1 [tables A1-A3 available online]). Sample sizes were not significantly different between islands (Wilcoxon rank-sum statistic $=28.5$, $n=7$ and $9, P>.75)$. We focused on adult male lizards for this study because females are less well represented in museum collections. We identified males by the presence of enlarged postanal scales and a visibly enlarged throat fan (dewlap), and we measured snout-vent length (SVL), using digital calipers, to the nearest $0.01 \mathrm{~mm}$. We recorded SVL as the distance between the tip of the snout and the opening of the cloaca. One person (J.E.W.) performed all measurements, which were taken twice per lizard to assure that deviation between the measurements was less than 1\%; if it was not, a third measurement was taken. We retained the average of these measurements as the body size for each lizard. To control for body size evolution caused by factors unrelated to temperature that can occur on small, offshore islands, such as niche expansion and ecological release (Schoener 1969; Lister 1976a, 1976b), we restricted our analyses to individuals from mainland Cuba and Hispaniola. Body size and elevation data are deposited in the Dryad Digital Repository: http://dx.doi.org/10.5061/dryad.q39h2 (Muñoz et al. 2014b).

\section{Regression Models and Hypothesis Testing}

To test hypotheses of how body size varies with elevation within and among species (H1-H8; fig. 1), we fitted a series of linear models to the cybotes (Hispaniola) and sagrei (Cuba) clades. Figure 1 depicts how inverse clines, commonly observed in squamates (Ashton and Feldman 2003), may arise through the combination of intraspecific and interspecific effects. We used these models to evaluate our eight hypotheses by testing whether incorporating 
slope and/or intercept differences explained significantly more variation than simpler models, using ANOVA on marginal sums of squares. Testing the hypotheses requires assessing results from multiple models; specific predictions and how they were tested with the various regression models are described in table 1.

Model 1 was a simple linear regression of SVL on elevation, pooling all species within a clade; this assumed that all species shared a common intercept and slope (e.g., H1). Model 2 was a one-way ANOVA that tested for differences in mean SVL among species, assuming no intraspecific relationships between SVL and elevation (e.g., H2, H8). Model 3 was an ANCOVA that allowed intercepts of the SVL-elevation relationship to vary among species but constrained slopes to be equal; this model also allowed us to assess whether intra- and interspecific patterns worked in concert or in opposition (e.g., H3-H5). Finally, model 4 was an ANCOVA with an interaction that allowed both slopes and intercepts to vary, which allowed us to assess whether intra- and interspecific effects varied in strength and direction (e.g., H6, H7). Each of our hypotheses makes a number of predictions that can be tested by evaluating these models. For example, hypothesis $\mathrm{H} 1$ (fig. 1) predicts a significant relationship between SVL and elevation (model 1), no difference in species' intercepts after accounting for elevation (testing model 3 vs. model 1 ), and no difference in slopes between species (testing model 4 vs. model 3 ).

In all models, elevation was log transformed after addition of 0.5 , to reduce right skew. We accounted for vastly different sample sizes among species by weighting observations by the inverse of their species' sample size. This weighting ensured that the relationships were not dominated by a few prevalent species (e.g., A. sagrei on Cuba and $A$. cybotes on Hispaniola). Given that the interaction term in model 4 evaluates whether the slope of the SVLelevation relationship varies among species $(\mathrm{H} 6, \mathrm{H} 7)$ but not whether individual species' slopes differ from $0(\mathrm{H} 2$, $\mathrm{H} 8$ ), we also regressed SVL on elevation individually for each species.

Model 2 tests whether species' means differ but not whether those differences are related to elevation (e.g., H8 vs. H2). To test this, we calculated the mean SVL and mean elevation of each species. Using these mean values, we fitted another regression model (model 5) with species' mean SVL as the response variable and mean elevation as the predictor. Thus, for the cybotes clade (Hispaniola) $n=$ 7 , and for the sagrei clade (Cuba) $n=9$. Because a species' mean elevation and body size may be strongly affected by sampling variation along its elevational range, we also fitted model 5 using species' SVL and elevational midpoints rather than means. To account for relatedness among species, we used Mahler et al.'s (2010) maximum clade cred- ibility tree to fit model 5 for each clade with phylogenetic generalized least squares (PGLS), using the gls function in the nlme package (Pinheiro et al. 2013) in R, version 2.15.3 (R Development Core Team 2013), and assuming a Brownian motion (BM) model for body size evolution. We chose BM because it fits the data better than an Ornstein-Uhlenbeck model in all cases (change in corrected Akaike Information Criterion $\left[\Delta \mathrm{AIC}_{\mathrm{c}}\right]$ was $>4.8$ for all comparisons).

\section{Spatial Autocorrelation}

Specimens obtained from identical or nearby localities are not expected to be independent, because of dispersal, gene flow, relatedness, or other, unmeasured environmental variables. Following Dormann et al. (2007), we accounted for spatial autocorrelation by fitting generalized least squares (GLS) models, using the $g l s$ function in the nlme package (Pinheiro et al. 2013) in $\mathrm{R}$, version 2.15.3. We fitted each model with three different spatial correlation structures - exponential, Gaussian, and spherical—and selected the one with the lowest $\mathrm{AIC}_{\mathrm{c}}$ for further significance testing, as above. Many specimens were collected at identical localities. Thus, to avoid distances of 0 separating spatial neighbors, we added a random jitter to $X$ and $Y$ coordinates. These were randomly drawn from a normal distribution with a mean of 0 and a standard deviation of $0.1 \mathrm{~m}$. We repeated jittering 100 times, refitting GLS models each time. Results from GLS models were nearly identical to those from nonspatial models and led to the same conclusions; thus, spatial autocorrelation cannot account for the observed results. We present only nonspatial results below, and GLS results can be found in "Supplementary Material," available online.

\section{Comparing Elevational Range}

The detected relationships between elevation and body size within species may depend on a species' elevation range. However, we found no significant difference between the mean elevational range occupied by Hispaniolan species and that of Cuban species (Hispaniola: mean $\pm \mathrm{SE}=$ $904.7 \pm 247.8 \mathrm{~m}$; Cuba: mean $\pm \mathrm{SE}=462.8 \pm 170.1$ $\mathrm{m}, t=-1.52$, df $=14, P=.15)$. Furthermore, intraspecific clines may be easier to detect in species with wide elevational ranges. To test for this, we regressed the absolute value of individual species' SVL-elevation slope against elevation range, weighting points by the standard error of the slope estimate. After log-transforming individual species' regression slopes, because of highly skewed residuals, and pooling species from both islands, we found a negative relationship between individual absolute SVLelevation regression slopes and elevation range (fig. A1 [figs. 
A1-A3 available online]; general linear model slope \pm $\mathrm{SE}=-1.1 \times 10^{-3} \pm 4.6 \times 10^{-4}, t=-2.40, \mathrm{df}=14$, $P=.006)$. Thus, species with narrower ranges actually tended to have steeper body size clines, though not necessarily in a consistent direction. However, as species' elevational ranges did not differ among islands, this is unlikely to underlie any observed differences between the two clades.

\section{Results}

\section{Body Size-Elevation Relationships in the cybotes Clade (Hispaniola)}

We found that body size was negatively related to elevation on Hispaniola when data from all species were pooled together (model 1), indicating an inverse Bergmann's cline (fig. 2; slope $\pm \mathrm{SE}=-1.95 \pm 0.18, t=-10.60$, df $=$ $\left.433, P<10^{-15}\right)$. Elevation accounted for $21 \%$ of the variance in body size (table 2). Mean body sizes differed significantly among species (model 2; table 2) and accounted for $53 \%$ of the total variance. We also found that the intercepts, but not the slopes of the SVL-elevation relationships, varied among species (model 3), revealing that the negative Bergmann's cline was primarily due to inter- rather than intraspecific differences (table 2; fig. 2). In this model, species' intercepts were significantly different, even after elevation was accounted for, whereas the elevation term was not significant after intercept differences were accounted for (table 2). In addition, the percentage of variance uniquely attributable to intercept differences $(32 \%)$ was far greater than that uniquely attributable to elevation $(0.1 \%$; table 2$)$. Finally, we found no evidence that the slopes of body size relationships varied among species (fig. 2), as the interaction in model 4 was not significant (table 2).

The lack of a significant elevation effect in model 3 suggests that interspecific differences drive the inverse Bergmann's cline in the cybotes clade. The inverse relationship between species' mean SVL and mean elevation (model 5) further corroborates this interpretation (fig. 3; slope $\pm \mathrm{SE}=-4.27 \pm 0.99, t=-4.32, \mathrm{df}=5, P=$ $.008)$. Nearly identical results were obtained when species' midpoints, rather than means, were used (not shown) and when PGLS was used to account for relatedness among species $(P<.025$ for PGLS slopes). Finally, individual species' regressions of SVL on elevation revealed that slopes were not significantly different from 0 (table 3 ). The lack of significant intraspecific relationships, coupled with the overall inverse body size cline (model 1 ) and a negative cline in mean body size (model 5), is consistent with hypothesis $\mathrm{H} 2$ (fig. 1), in which the clade-level inverse cline is due solely to interspecific effects.

\author{
Body Size-Elevation Relationships in the \\ sagrei Clade (Cuba)
}

When species identity was ignored (model 1), we found that SVL decreased with elevation in the sagrei clade (fig. 2; slope $\pm \mathrm{SE}=-0.71 \pm 0.19, t=-3.78, \mathrm{df}=669$, $\left.P<2 \times 10^{-4}\right)$, but only weakly so, explaining only $2.1 \%$ of the variance (table 2). Thus, we detected an overall inverse Bergmann's cline for the sagrei clade anoles.

As with the cybotes clade anoles, there were significant differences among species' mean body sizes that explained $60 \%$ of the variance in SVL (model 2; table 2). However, in contrast to the results from Hispaniola, we recovered significant intraspecific relationships between body size and elevation in the Cuban sagrei clade (fig. 2; table 2). Specifically, the elevation term in model 3 remained statistically significant after species differences were incorporated, although it uniquely explained extremely little variance (table 2). This is in part because the SVL-elevation relationships differed among species (fig. 2; table 2). When the variance explained by model 3 was partitioned, we found that the intercept differences and elevation independently explained $59 \%$ and $0.7 \%$ of the variance, respectively (table 2). Allowing the slopes to vary (model 4) accounted for an additional $6.5 \%$, for a total of $67 \%$, demonstrating that intraspecific variation is slight relative to interspecific differences in SVL in this clade (table 2). However, interspecific differences were not responsible for overall SVL clines, as we found no significant relationship between species' mean SVL and mean elevation (model 5; fig. 3; slope $\pm \mathrm{SE}=0.21 \pm 1.97, t=0.11 \mathrm{df}=7, P=$ 0.92 ). These results were nearly identical when midpoints, rather than means, were used (not shown) and remained nonsignificant when PGLS was used $(P>.55$ for both mean and midpoint analysis). Regressions of SVL on elevation for individual species revealed that body size decreased significantly with elevation in five out of nine species (A. allogus, A. homolechis, A. jubar, A. sagrei, and A. quadriocellifer, fig. 3; table 3 ). These results closely mirrored those from our GLS analysis, with the exception of A. ahli. Although A. ahli's body size apparently increased with elevation, this relationship was not significant in our GLS analysis (table A3). In summary, as with the cybotes clade anoles, the sagrei clade anoles exhibited an inverse Bergmann's cline. However, unlike in the cybotes clade, there was no clear interspecific cline for the sagrei clade. Rather, within species, several species showed significant body size-elevation relationships. Given that strength and direction of the size clines differed, our results are most consistent with hypothesis $\mathrm{H7}$ for the sagrei clade on Cuba.

\section{Discussion}

The cybotes and sagrei clades both exhibit an inverse Bergmann's cline; lizards tend to be smaller at high elevations 

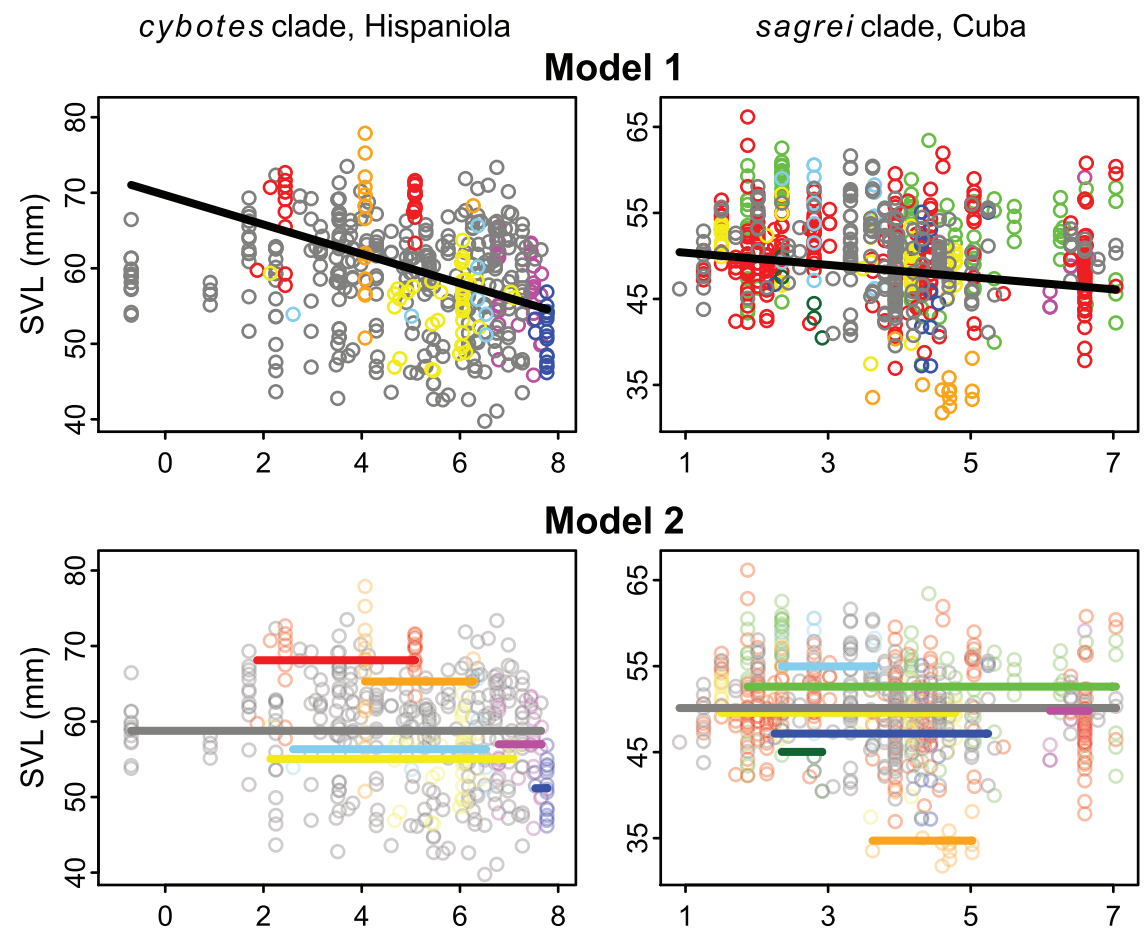

Model 4
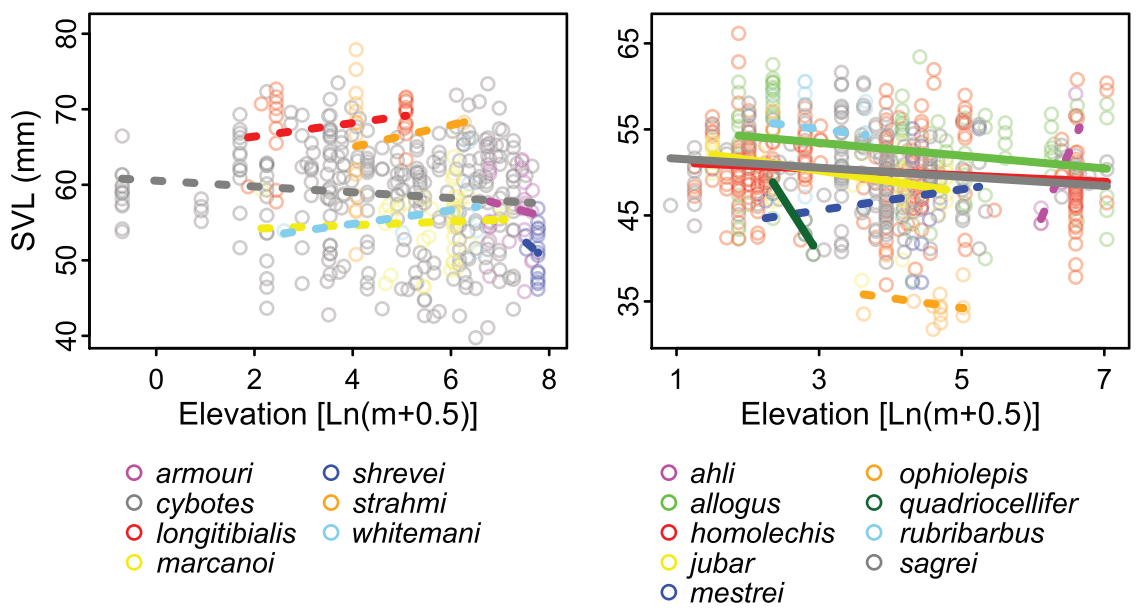

Figure 2: Body size (snout-vent length [SVL])-elevation relationships for the cybotes clade on Hispaniola and the sagrei clade on Cuba. Model 1 fitted a single relationship to all species $(P<.05$ in both cases). Model 2 constrained slopes at 0 and allowed intercepts to vary $(P<.05$ in both cases), and model 4 allowed slopes and intercepts to vary; dashed lines depict slopes that were not significant $(P>.05)$ in generalized least squares models that incorporated spatial autocorrelation (table A2, available online). To ensure that the best-fit lines are visible, points are faded for models 2 and 4 . Model 3 is not shown because the value of the common slope is arbitrary. Results for the cybotes clade are consistent with hypothesis H2, whereas results for the sagrei clade are consistent with hypothesis H7 (fig. 1).

than near sea level. Inverse Bergmann's clines have been previously documented in squamates (Ashton and Feldman 2003; Olalla-Tárraga et al. 2006), although they are by no means ubiquitous (Pincheira-Donoso and Meiri 2013). Inverse size clines may arise from a number of mechanisms. First, small body sizes at high elevations may be adaptive for thermoregulation. Because of their greater surface area-to-volume ratio, smaller-bodied individuals warm and cool more rapidly, which may allow them to more precisely thermoregulate in cold montane environments (Ashton and Feldman 2003; Sears and Angilletta 2004). 


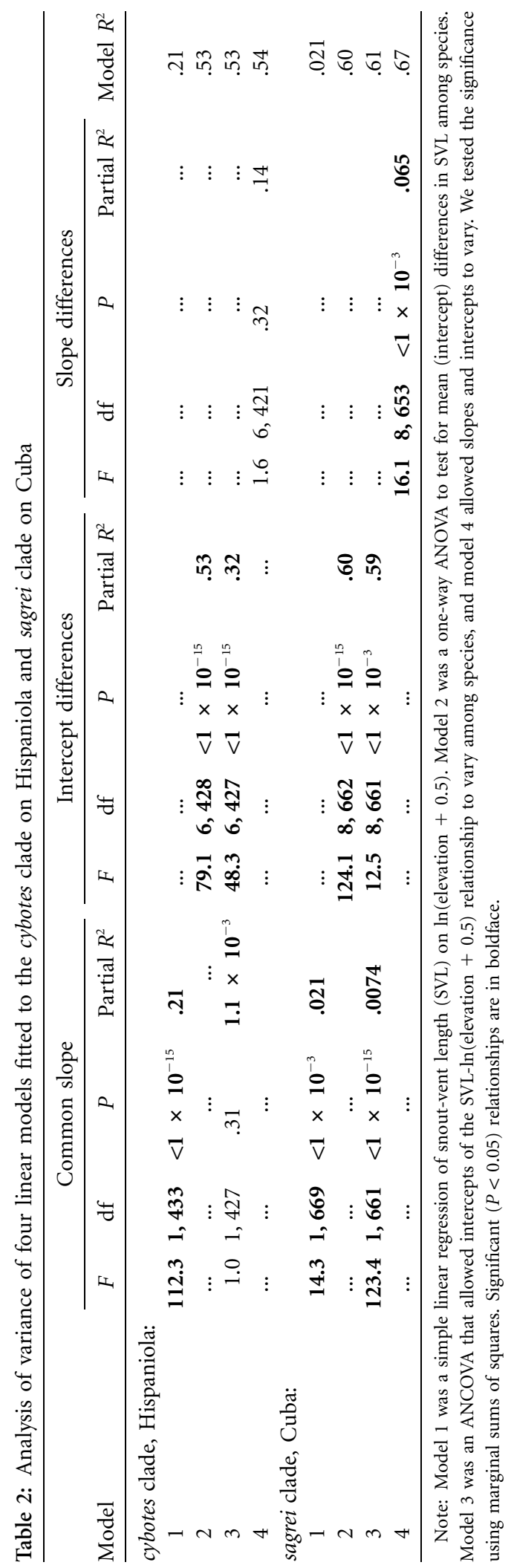



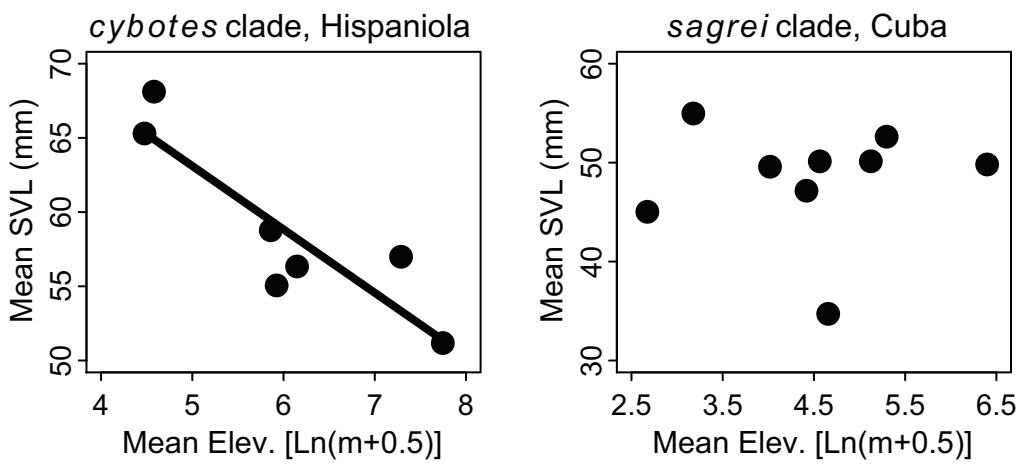

Figure 3: Relationship between species' mean body size (snout-vent length [SVL]) and the mean elevation of their sampled localities for the cybotes clade on Hispaniola $(P<.01)$ and the sagrei clade on Cuba $(P>.90)$. The relationships were nearly identical when midpoints, rather than means, were used (not shown).

Indeed, previous work has demonstrated that montane lizards in the Hispaniolan cybotes clade thermoregulate during the day at temperatures comparable to those for their lowland counterparts (Hertz and Huey 1981; Muñoz et al. 2014a). Low thermal inertia may aid this thermoregulatory behavior of smaller montane lizards. Current evidence suggests that body temperatures and basking tendencies differ considerably among species in the sagrei clade (Ruibal 1961; Rodríguez Schettino et al. 2010; Hertz et al. 2013). Thus, it seems possible that lizard species in the two clades show different relationships between body size and thermoregulatory behavior. However, given that the anoles examined are all relatively small-bodied lizards, it also remains unclear whether the magnitude of size differences among species is sufficient to significantly alter thermal inertia.

Inverse size clines may also reflect differences in life history between low- and high-elevation lizards. Colder temperatures typically slow growth in ectotherms. This slower growth may produce smaller adult body size if colder temperatures also reduce survival to maturity or reduce fecundity, relative to lizards inhabiting warmer temperatures (Angilletta et al. 2004a, 2004b; but see Sears and Angilletta 2004). Given that high-elevation lizards in the cybotes clade retain their eggs until a later developmental stage before laying (Huey 1977) and that anoles lay one egg at a time (discussed in Losos 2009), it is possible that smaller body size at maturity may serve to compensate for reduced fecundity in montane species. Alternatively, smaller body size at high elevation may also be nonadaptive and may be the result of reduced activity times that limit growth (Sears and Angilletta 2004; Caruso et al. 2014). Finally, individuals are also subject to a range of abiotic and biotic selection pressures beyond temperature, including but not limited to microhabitat availability, competition, predation, disease, and resource avail- ability, all of which may influence body size (Angilletta et al. 2004b; Pincheira-Donoso and Meiri 2013).

Although the precise mechanisms underlying inverse size clines remain unknown, it is clear that they were constructed in different ways on Cuba and Hispaniola. For the Hispaniolan cybotes clade, interspecific size differences are responsible for the cline, with little or no evidence for intraspecific contributions ( $\mathrm{H} 2$ in fig. 1). Thus, the cybotes clade cline reflects the evolutionary divergence of species' body size, coupled with size-ordered species turnover, or the replacement of larger species with smaller ones as elevation increases (Blackburn et al. 1999; Ackerly and Cornwell 2007; Lepš et al. 2011). Alternatively, in the Cuban sagrei clade, intraspecific body size clines are responsible for the overall inverse Bergmann's cline, with no evidence for contributions from interspecific body size differences. We suggest that these results are consistent with hypothesis H7 (fig. 1), as there are varying intraspecific patterns but no clear interspecific cline. Thus, in this clade, variation in local adaptation and/or phenotypic plasticity likely underlies the cline, rather than evolutionary divergence in body size among species.

The differential roles of interspecific and intraspecific processes between the two clades raise many questions, especially because the adaptive radiation of Caribbean anoles is characterized by replicated, convergent evolution in microhabitat use and functional adaptations (Williams 1972, 1983; Losos 2009). One possibility is that differences in the physical geography of Cuba and Hispaniola may underlie the different patterns observed on each island. Hispaniola's highland areas (sensu Wollenberg et al. 2013) and their associated climatic gradients are far more extensive than those on Cuba. Hispaniola harbors 7,940 $\mathrm{km}^{2}$ of habitat more than $1,000 \mathrm{~m}$ above sea level, whereas Cuba has only $271 \mathrm{~km}^{2}$ of highland habitat. The greater extent of climatically extreme habitats suggests a greater 
Table 3: Body size-elevation relationships for individual Anolis species in the cybotes clade on Hispaniola and the sagrei clade on Cuba

\begin{tabular}{lcrrll}
\hline Species & Slope $(\mathrm{SE})$ & $t$ & $\mathrm{df}$ & $P$ & $R^{2}$ \\
\hline cybotes clade, Hispaniola: & & & & & \\
A. armouri & $-1.83(2.69)$ & -.68 & 27 & .50 & .017 \\
A. cybotes & $-.38(.20)$ & -1.93 & 298 & .055 & .012 \\
A. longitibialis & $.89(.56)$ & 1.58 & 24 & .13 & .095 \\
A. marcanoi & $.24(.84)$ & .28 & 38 & .78 & .0021 \\
A. shrevei & $-5.59(10.69)$ & -.52 & 15 & .61 & .018 \\
A. strahmi & $1.45(3.59)$ & .40 & 14 & .69 & .011 \\
A. whitemani & $.90(1.46)$ & .044 & 5 & .57 & .070 \\
sagrei clade, Cuba: & & & & & \\
A. ahli & $\mathbf{1 9 . 7 5 ( 5 . 0 0 )}$ & $\mathbf{3 . 9 5}$ & $\mathbf{7}$ & $\mathbf{. 0 0 5 5}$ & $\mathbf{. 6 9}$ \\
A. allogus & $-.75(.33)$ & $-\mathbf{2 . 2 4}$ & $\mathbf{9 4}$ & $\mathbf{. 0 2 8}$ & $\mathbf{. 0 5 1}$ \\
A. homolechis & $-.37(.16)$ & $-\mathbf{2 . 3 4}$ & $\mathbf{2 6 6}$ & $\mathbf{. 0 2 0}$ & $\mathbf{. 0 2 0}$ \\
A. jubar & $-\mathbf{1 . 2 5}(.39)$ & $-\mathbf{3 . 1 7}$ & $\mathbf{4 3}$ & $\mathbf{. 0 0 2 8}$ & $\mathbf{. 1 9}$ \\
A. mestrei & $1.22(2.88)$ & .42 & 11 & .68 & .016 \\
A. ophiolepis & $-1.14(1.65)$ & -.69 & 11 & .50 & .042 \\
A. quadriocellifer & $-\mathbf{1 2 . 9 8}(\mathbf{2 . 6 2})$ & $-\mathbf{4 . 9 6}$ & $\mathbf{3}$ & $\mathbf{. 0 1 6}$ & $\mathbf{. 8 9}$ \\
A. rubribarbus & $-1.03(2.45)$ & -.42 & 14 & .68 & .013 \\
A. sagrei & $-.53(.26)$ & $-\mathbf{2 . 0 3}$ & $\mathbf{2 0 4}$ & $\mathbf{. 0 4 3}$ & $\mathbf{. 0 2 0}$
\end{tabular}

Note: Body size was measured as snout-vent length. Elevation was natural log transformed (after adding 0.5). Significant $(P<0.05)$ models are in boldface. These results were closely mirrored in the generalized least squares analysis, except for A. ahli (table A3, available online).

potential for reduced dispersal and isolation by environment along tropical elevational gradients (sensu Janzen 1967) in Hispaniola. Given that speciation depends on an area threshold on oceanic islands (Losos and Schluter 2000; Kisel and Barraclough 2010; Losos and Parent 2010), the same may be true for highland habitat. Hispaniola's extensive highland environments may create ecological isolation that triggers speciation. This speciation may be preceded or followed by selection for reduced body size. Importantly, the ecological isolation would more likely produce stronger interspecific clines while reducing intraspecific variation. Conversely, climatically extreme habitat is more rare on Cuba. As a result, higher gene flow across elevations may have enabled the broader intraspecific clines to arise here.

The intraspecific clines observed in the Cuban sagrei clade varied considerably in strength and direction. Body size is important for multiple dimensions of an organism's biology, including physiology, ecology, and life history. Thus, body size is likely under various types of selection at the same time that may work in concert or in opposition to shape clinal patterns. For example, geographic variation in sexual selection is known to enhance or erode body size clines, particularly in species that exhibit sexual size dimorphism (Storz et al. 2001; Blanckenhorn et al. 2006). In anoles, sexual selection may promote large male size to aid defense of territories and to increase access to mating opportunities (reviewed in Butler et al. 2000; Losos 2009). Thus, variation in the strength and direction of intra- specific clines in male body size may reflect a combined response to sexual and natural selection, possibly to the extent that narrowly restricted species exhibit steeper clines than broadly distributed species, as we observed. Females in the sagrei clade exhibit much less variation in body size than males (Henderson and Powell 2009). This point highlights that our findings stem only from males. Although female size is likely correlated with male size, it remains unknown whether intraspecific or interspecific variation creates body size-elevation clines on these islands.

In this article, we introduced an approach that is widely applicable for parsing out the contributions of intra- and interspecific variation to trait-environment relationships. We found that patterns apparent at the level of clades may be absent or nearly so at the level of species, and vice versa. Thus, similar clinal patterns in body size can be constructed from different ecological and evolutionary processes. Our results demonstrate that restricting analyses of Bergmann's rule (or other ecogeographical patterns) solely to either the intra- or interspecific level may miss important trait-environment relationships and, consequently, may affect inferences of their underlying ecological and evolutionary factors. The analyses we present here show that mechanisms underlying biogeographic patterns should be considered in a framework that explicitly considers how local adaption and trait divergence during speciation can produce similar patterns. Integrating both intra- and interspecific effects can improve our understanding of how geographic patterns in trait distributions 
emerge and may prove useful to explain a wide variety of evolutionary phenomena.

\section{Acknowledgments}

We thank R. Field, S. Hall, S. Lambert, J. Losos, L. Mahler, S. Meiri, Y. Stuart, and two anonymous reviewers, whose helpful feedback greatly improved this article. J. Rosado and the staff of the Museum of Comparative Zoology at Harvard University kindly provided access to specimens A National Science Foundation Graduate Research Fellowship grant provided financial support to M.M.M., and the University of Munich EES (Evolutionary Genomics, Ecology and Systematics) Travel Fund and a PROMOS (Programm zur Steigerung der Mobilität von deutschen Studierenden) stipend provided support to J.E.W.

\section{Literature Cited}

$\rightarrow$ Ackerly, D. D., and W. K. Cornwell. 2007. A trait-based approach to community assembly: partitioning of species trait values into within- and among-community components. Ecology Letters 10: 135-145.

$\rightarrow$ Angilletta, M. A., Jr., P. H. Niewiarowski, A. E. Dunham, A. D. Leaché, and W. P. Porter. 2004a. Bergmann's clines in ectotherms: illustrating a life-history perspective with sceloporine lizards. American Naturalist 164:E168-E183.

$\rightarrow$ Angilletta, M. A., Jr., T. D. Steury, and M. W. Sears. 2004b. Temperature, growth rate, and body size in ectotherms: fitting pieces of a life-history puzzle. Integrative and Comparative Biology 44: 498-509.

$\rightarrow$ Ashton, K. G., and C. R. Feldman. 2003. Bergmann's rule in nonavian reptiles: turtles follow it, lizards and snakes reverse it. Evolution 57:1151-1163.

Bergmann, K. 1847. Über die Verhältnisse der Wärmeökonomie der Thiere zu ihrer Grösse. Göttinger Studien 3:595-708.

$\rightarrow$ Blackburn, T. M., K. J. Gaston, and N. Loder. 1999. Geographic gradients in body size: a clarification of Bergmann's rule. Diversity and Distributions 5:165-174.

$\rightarrow$ Blanckenhorn, W. U., R. G. Stillwell, K. A. Young, C. W. Fox, anc K. G. Ashton. 2006. When Rensch meets Bergmann: does sexual size dimorphism change systematically with latitude? Evolution 60:2004-2011.

$\rightarrow$ Butler, M. A., T. W. Schoener, and J. B. Losos. 2000. The relationship between sexual size dimorphism and habitat use in Greater An tillean Anolis lizards. Evolution 54:259-272.

$\rightarrow$ Caruso, N. M., M. W. Sears, D. C. Adams, and K. R. Lips. 2014 Widespread rapid reductions in body size of salamanders in response to climate change. Global Change Biology 20:1751-1759.

$\rightarrow$ Chown, S. L., and K. J. Gaston. 2010. Body size variation in insects. a macroecological perspective. Biological Reviews 85:139-169.

$\rightarrow$ de Queiroz, A., and K. G. Ashton. 2004. The phylogeny of a specieslevel tendency: species heritability and possible deep origins of Bergmann's rule in tetrapods. Evolution 58:1674-1684.

$\rightarrow$ Dormann, C. F., J. M. McPherson, M. B. Araújo, R. Bivand, J. Bolliger, G. Carl, R. G. Davies, et al. 2007. Methods to account for spatial autocorrelation in the analysis of species distributional data: a review. Ecography 30:609-628.

$\rightarrow$ Glor, R. E., J. J. Kolbe, R. Powell, A. Larson, and J. B. Losos. 2003. Phylogenetic analysis of ecological and morphological diversification in Hispaniolan trunk-ground anoles (Anolis cybotes group). Evolution 57:2383-2397.

Henderson, R. W., and R. Powell. 2009. Natural history of West Indian reptiles and amphibians. University Press of Florida, Gainesville.

Hertz, P. E., Y. Arima, A. Harrison, R. B. Huey, J. B. Losos, and R. E. Glor. 2013. Asynchronous evolution of physiology and morphology in Anolis lizards. Evolution 67:2101-2113.

Hertz, P. E., and R. B. Huey. 1981. Compensation for altitudinal changes in the thermal environment by some Anolis lizards on Hispaniola. Ecology 62:515-521.

Huey, R. B. 1977. Egg retention in some high-altitude Anolis lizards. Copeia 1977:373-375.

$\rightarrow$ James, F. C. 1970. Geographic size variation in birds and its relationship to climate. Ecology 51:365-390.

$\rightarrow$ Janzen, D. H. 1967. Why mountain passes are higher in the tropics. American Naturalist 101:233-249.

$\rightarrow$ Kisel, Y., and T. G. Barraclough. 2010. Speciation has a spatial scale that depends on levels of gene flow. American Naturalist 175:316334.

Knouft, J. H., J. B. Losos, R. E. Glor, and J. J. Kolbe. 2006. Phylogenetic analysis of the evolution of the niche in lizards of the Anolis sagrei group. Ecology 87:S29-S38.

Lepš, J., F. de Bello, P. Šmilauer, and J. Doležal. 2011. Community trait response to environment: disentangling species turnover vs intraspecific trait variability effects. Ecography 34:856-863.

Lister, B. C. 1976a. The nature of niche expansion in West Indian Anolis lizards. I. Ecological consequences of reduced competition. Evolution 30:659-676.

1976b. The nature of niche expansion in West Indian Anolis lizards. II. Evolutionary components. Evolution 30:677-692.

Losos, J. B. 2009. Lizards in an evolutionary tree: ecology and adaptive radiation of anoles. University of California Press, Berkeley.

Losos, J. B., and C. E. Parent. 2010. The speciation-area relationship. Pages 415-438 in J. B. Losos and R. E. Ricklefs, eds. The theory of island biogeography revisited. Princeton University Press, Princeton, NJ.

Losos, J. B., and D. Schluter. 2000. Analysis of an evolutionary species-area relationship. Nature 408:847-850.

Mahler, D. L., L. J. Revell, R. E. Glor, and J. B. Losos. 2010. Ecological opportunity and the rate of morphological evolution in the diversification of Greater Antillean anoles. Evolution 64:2731-2745.

$\rightarrow$ Mayr, E. 1956. Geographical character gradients and climatic adaptation. Evolution 10:105-108.

Meiri, S. 2011. Bergmann's rule-what's in a name? Global Ecology and Biogeography 20:203-207.

Meiri, S., and G. H. Thomas. 2007. The geography of body sizechallenges of the interspecific approach. Global Ecology and Biogeography 16:689-693.

Muñoz, M. M., M. A. Stimola, A. C. Algar, A. Conover, A. Rodriguez, M. A. Landestoy, G. S. Bakken, and J. B. Losos. 2014a. Evolutionary stasis and lability in thermal physiology in a group of tropical lizards. Proceedings of the Royal Society B: Biological Sciences 281: 20132433. doi:10.1098/rspb.2013.2433.

Muñoz, M. M., J. E. Wegener, and A. C. Algar. 2014b. Data from: Untangling intra- and interspecific effects on body size clines re- 
veals divergent processes structuring convergent patterns in Anolis lizards. American Naturalist, Dryad Digital Repository, http://dx .doi.org/10.5061/dryad.q39h2.

Olalla-Tárraga, M. Á. 2011. "Nullius in Bergmann" or the pluralistic approach to ecogeographical rules: a reply to Watt et al. (2010). Oikos 120:1441-1444.

$\rightarrow$ Olalla-Tárraga, M. Á., M. Á. Rodríguez, and B. A. Hawkins. 2006. Broad-scale patterns of body size in squamate reptiles of Europ and North America. Journal of Biogeography 33:781-793.

$\rightarrow$ Phillimore, A. B., J. D. Hadfield, O. R. Jones, and R. J. Smithers. $\rightarrow$ 2010. Differences in spawning date between populations of common frog reveal local adaptation. Proceedings of the National Academy of Sciences of the USA 107:8292-8297.

$\rightarrow$ Phillimore, A. B., S. Stålhandske, R. J. Smithers, and R. Bernard. 2012. Dissecting the contributions of plasticity and local adaptation to the phenology of a butterfly and its host plants. American Naturalist 180:655-670.

$\rightarrow$ Pincheira-Donoso, D., D. J. Hodgson, and T. Tregenza. 2008. The evolution of body size under environmental gradients in ectotherms: why should Bergmann's rule apply to lizards? BMC Evolutionary Biology 8:68-78.

$\rightarrow$ Pincheira-Donoso, D., and S. Meiri. 2013. An intercontinental analysis of climate-driven body size clines in reptiles: no support for patterns, no signals of processes. Evolutionary Biology 40:562-578.

Pinheiro, J., D. Bates, S. DebRoy, D. Sarkar, and the R Development Core Team. 2013. nlme: linear and nonlinear mixed effects models R package version 3.1-113. http://cran.r-project.org/web/packages /nlme/index.html.

R Development Core Team. 2013. R: a language and environment for statistical computing. R Foundation for Statistical Computing, Vienna, Austria.

$\rightarrow$ Rensch, B. 1938. Some problems of geographical variation and species formation. Proceedings of the Linnean Society of London 150: 275-285.

$\rightarrow$ Rodríguez Schettino, L., J. B. Losos, P. E. Hertz, K. de Queiroz, A. R. Chamizo, M. Leal, and V. R. González. 2010. The anoles of Soroa: aspects of their ecological relationships. Breviora 520:1-22.

$\rightarrow$ Ruibal, R. 1961. Thermal relations of five species of tropical lizards. Evolution 15:98-111.

Schoener, T. W. 1969. Size patterns in West Indian Anolis lizards. I. Size and species diversity. Systematic Zoology 18:386-401.

Sears, M. W., and M. J. Angilletta Jr. 2004. Body size clines in Sceloporus lizards: proximate mechanisms and demographic constraints. Integrative and Comparative Biology 44:433-442.

$\rightarrow$ Shelomi, M. 2012. Where are we now? Bergmann's rule sensu lato in insects. American Naturalist 180:511-519.

Storz, J. F., J. Balasingh, H. R. Bhat, P. T. Nathan, D. P. Swami Doss, A. A. Prakash, and T. H. Kunz. 2001. Clinal variation in body size and sexual dimorphism in an Indian fruit bat, Cynopterus sphinx (Chiroptera: Pteropodidae). Biological Journal of the Linnean Society $72: 17-31$.

Williams, E. E. 1972. The origin of faunas. Evolution of lizard congeners in a complex island fauna: a trial analysis. Evolutionary Biology 6:47-89.

- 1983. Ecomorphs, faunas, island size, and diverse end points in island radiations of Anolis. Pages 326-370 in R. B. Huey, E. R. Pianka, and T. W. Schoener, eds. Lizard ecology: studies of a model organism. Harvard University Press, Cambridge, MA.

$\rightarrow$ Wollenberg, K. C., I. J. Wang, R. E. Glor, and J. B. Losos. 2013. Determinism in the diversification of Hispaniolan trunk-ground anoles (Anolis cybotes species complex). Evolution 67:3175-3190.

Associate Editor: Spencer R. Hall Editor: Judith L. Bronstein

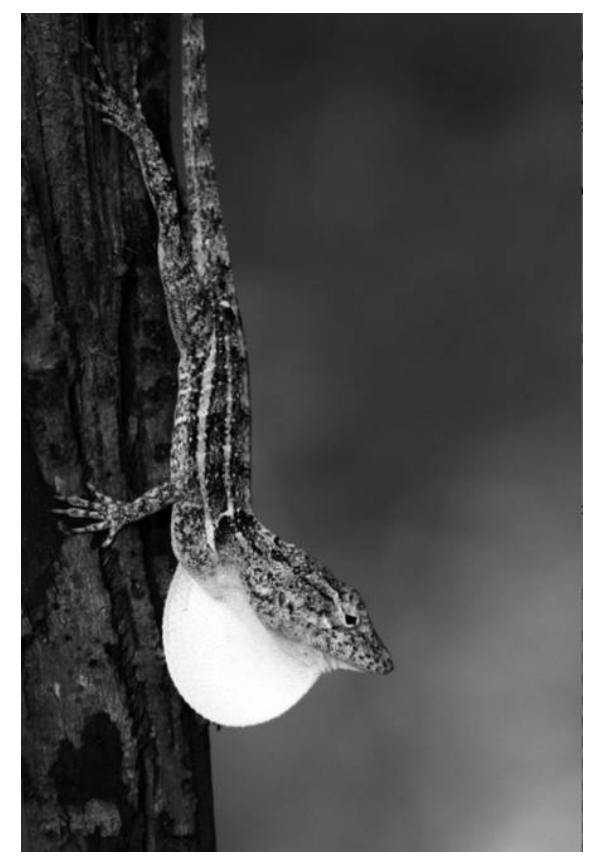

Anolis whitemani, a low- to midelevation species from Hispaniola. Photo by Miguel A. Landestoy, used with permission. 


\title{
Appendix from M. M. Muñoz et al., 'Untangling Intra- and Interspecific Effects on Body Size Clines Reveals Divergent Processes Structuring Convergent Patterns in Anolis Lizards"
}

\author{
(Am. Nat., vol. 184, no. 5, p. 636)
}

\section{Supplementary Material and Spatial Regression Results}

\section{Supplementary Material}

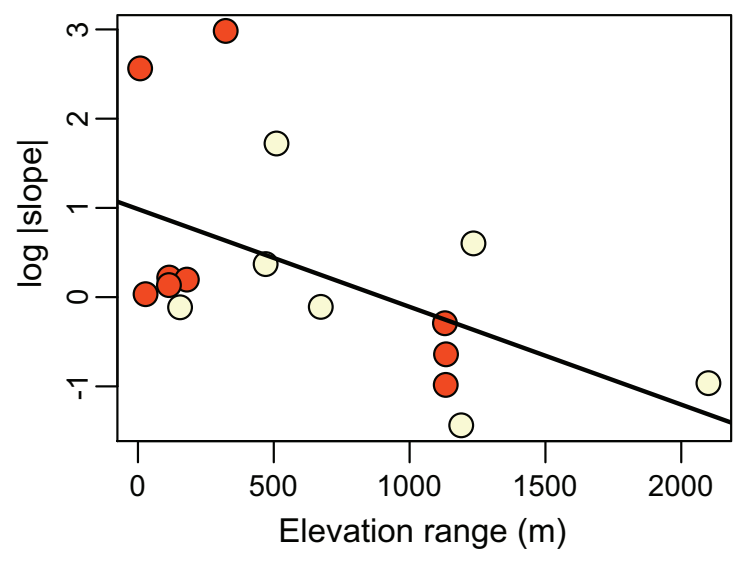

Figure A1: Relationship between the absolute slope of the body size-elevation regression and the elevation range of 16 species of anole from the cybotes clade on Hispaniola (light yellow) and the sagrei clade on Cuba (orange-red). Absolute slopes were log transformed to reduce skew of residuals.

Table A1. Summary statistics for the 16 Anolis species in this study

\begin{tabular}{|c|c|c|c|c|c|c|}
\hline \multirow[b]{2}{*}{ Clade, species } & \multirow[b]{2}{*}{$N$} & \multirow[b]{2}{*}{ Unique $X, Y$} & \multicolumn{2}{|c|}{ Elevation (m) } & \multicolumn{2}{|c|}{ Body size (mm) } \\
\hline & & & Mean (SD) & Range & Mean (SD) & Range \\
\hline \multicolumn{7}{|c|}{ cybotes clade, Hispaniola: } \\
\hline A. armouri & 29 & 6 & $1,462(482)$ & $887-2,122$ & $57(5.1)$ & $45.9-65.5$ \\
\hline A. cybotes & 300 & 75 & $350(437)$ & $0-2,100$ & $58.8(7)$ & $39.8-73.5$ \\
\hline A. longitibialis & 26 & 6 & $97(76)$ & $6-161$ & $68.1(4)$ & $57.7-72.7$ \\
\hline A. marcanoi & 40 & 22 & $374(237)$ & $8-1,198$ & $55.1(4.3)$ & $46.4-63.7$ \\
\hline A. shrevei & 17 & 4 & $2,312(165)$ & $1,871-2,381$ & $51.2(3.3)$ & $46.2-56.9$ \\
\hline A. strahmi & 16 & 2 & 87 (118) & $58-528$ & $65.3(7.4)$ & $50.8-77.9$ \\
\hline A. whitemani & 7 & 4 & $467(271)$ & $13-686$ & $56.3(5)$ & $51.2-65.6$ \\
\hline \multicolumn{7}{|l|}{ sagrei clade, Cuba: } \\
\hline A. ahli & 9 & 4 & $600(129)$ & $451-774$ & $49.8(5.2)$ & $44.1-59.1$ \\
\hline A. allogus & 96 & 17 & 199 (299) & $6-1,136$ & $52.6(5.6)$ & $37.4-63.4$ \\
\hline A. homolechis & 268 & 39 & $167(280)$ & $3-1,136$ & $50.1(4.5)$ & $36.9-66.2$ \\
\hline A. jubar & 45 & 8 & $55(42)$ & $4-119$ & $49.6(3.5)$ & $37.5-57.2$ \\
\hline A. mestrei & 13 & 5 & $82(38)$ & $9-189$ & $47.2(6.4)$ & $37.2-55.1$ \\
\hline A. ophiolepis & 13 & 7 & $105(35)$ & $37-151$ & $34.7(2.3)$ & $31.8-40.4$ \\
\hline A. quadriocellifer & 5 & 3 & $14(4)$ & $10-18$ & $45(3.7)$ & $40.5-49.9$ \\
\hline A. rubribarbus & 16 & 4 & $24(12)$ & $10-38$ & $55(4.5)$ & $46.2-60.6$ \\
\hline A. sagrei & 206 & 39 & $96(180)$ & $2-1,136$ & $50.1(4.4)$ & $39.5-61.6$ \\
\hline
\end{tabular}

Note: "Unique $X, Y$ " is the number of unique localities for each species. Body size was measured as snout-vent length. 


\section{Spatial Regression Results}

\section{Body Size-Elevation Relationships in the cybotes Clade (Hispaniola)}

We found a significant inverse body size cline, pooling data from all species (model 1; table A2). As for the nonspatial analysis, this inverse cline arose because of interspecific differences. Even after elevation was accounted for, species had significantly different intercepts, but not vice versa (model 3; table A2). Furthermore, slopes did not differ among species. As with nonspatial analysis, regressing each species' SVL against elevation revealed no significant intraspecific relationships (table A3).

Table A2. Significance tests of four generalized least squares models fitted to the cybotes clade on Hispaniola and sagrei clade on Cuba to account for spatial autocorrelation while evaluating the relationship between snout-vent length and elevation $(\ln ($ elevation +0.5$))$

\begin{tabular}{|c|c|c|c|c|c|c|c|c|c|c|c|}
\hline \multirow[b]{2}{*}{ Model } & \multirow{2}{*}{$\begin{array}{c}\text { Spatial } \\
\text { correlation } \\
\text { structure }\end{array}$} & \multicolumn{3}{|c|}{ Common slope } & \multicolumn{3}{|c|}{ Intercept differences } & \multicolumn{4}{|c|}{ Slope differences } \\
\hline & & $F$ & df & $P$ & $F$ & $\mathrm{df}$ & $P$ & $F$ & df & & $P$ \\
\hline \multicolumn{12}{|c|}{ cybotes clade, Hispaniola: } \\
\hline 1 & Exponential & 59.4 & 1,433 & $<\mathbf{1} \times \mathbf{1 0}^{-13}$ & $\ldots$ & $\ldots$ & $\ldots$ & $\ldots$ & $\ldots$ & & $\ldots$ \\
\hline 2 & Exponential & $\ldots$ & $\ldots$ & $\ldots$ & 76.9 & 6,428 & $<\mathbf{1} \times \mathbf{1 0}^{-15}$ & $\ldots$ & $\ldots$ & & $\ldots$ \\
\hline 3 & Gaussian & 1.0 & 1,427 & .32 & 46.8 & 6,427 & $<\mathbf{1} \times \mathbf{1 0}^{-15}$ & $\ldots$ & $\ldots$ & & $\ldots$ \\
\hline 4 & Exponential & $\ldots$ & $\ldots$ & $\ldots$ & $\ldots$ & $\ldots$ & $\ldots$ & 1.57 & 6,421 & .15 & \\
\hline \multicolumn{12}{|c|}{ sagrei clade, Cuba: } \\
\hline 1 & Exponential & 8.4 & 1,669 & .0038 & $\ldots$ & $\ldots$ & $\ldots$ & $\ldots$ & $\ldots$ & & $\ldots$ \\
\hline 2 & Spherical & $\ldots$ & $\ldots$ & $\ldots$ & 122.3 & 8,662 & $<\mathbf{1} \times \mathbf{1 0}^{-15}$ & $\ldots$ & $\ldots$ & & $\ldots$ \\
\hline 3 & Gaussian & 11.9 & 1,661 & $5.1 \times 10^{-4}$ & 131.5 & 8,661 & $<\mathbf{1} \times \mathbf{1 0}^{-15}$ & $\ldots$ & $\ldots$ & & $\ldots$ \\
\hline 4 & Spherical & $\ldots$ & $\ldots$ & $\ldots$ & $\ldots$ & $\ldots$ & $\ldots$ & 15.6 & 8,653 & $<1 \times$ & $\times 10^{-15}$ \\
\hline
\end{tabular}

Table A3. Generalized least squares (GLS) models showing the body size-elevation relationships for individual Anolis species

\begin{tabular}{|c|c|c|c|c|c|c|}
\hline Species & Median slope (SE) & $t$ & df & $P$ & $\begin{array}{c}\text { Spatial } \\
\text { correlation } \\
\text { structure }\end{array}$ & $\begin{array}{c}\text { Models with } \\
P<.05\end{array}$ \\
\hline \multicolumn{7}{|c|}{ cybotes clade, Hispaniola: } \\
\hline A. armouri & $-1.83(2.69)$ & -.68 & 27 & .50 & Gaussian & 0 \\
\hline A. cybotes & $-.38(.20)$ & -1.93 & 298 & .055 & Spherical & 14 \\
\hline A. longitibialis & $.89(.56)$ & 1.58 & 24 & .13 & Spherical & 2 \\
\hline A. marcanoi & $.22(.84)$ & .26 & 38 & .80 & Gaussian & 0 \\
\hline A. shrevei & $-5.59(10.69)$ & -.52 & 15 & .61 & Exponential & 0 \\
\hline A. strahmi & $1.45(3.59)$ & .40 & 14 & .69 & Gaussian & 0 \\
\hline A. whitemani & $.90(1.46)$ & 61 & 5 & .57 & Exponential & 0 \\
\hline \multicolumn{7}{|l|}{ sagrei clade, Cuba: } \\
\hline A. ahli & $17.34(7.41)$ & 2.34 & 7 & .052 & Exponential & 28 \\
\hline A. allogus & $-.70(.34)$ & -2.09 & 94 & .039 & Gaussian & 53 \\
\hline A. homolechis & $-.33(.16)$ & -2.01 & 266 & .046 & Exponential & 52 \\
\hline A. jubar & -1.25 (0.39) & -3.17 & 43 & .0028 & Gaussian & 99 \\
\hline A. mestrei & $1.22(2.88)$ & .42 & 11 & .68 & Exponential & 0 \\
\hline A. ophiolepis & $-1.44(1.65)$ & -.69 & 11 & .50 & Exponential & 0 \\
\hline A. quadriocellifer & $-12.98(2.61)$ & -4.96 & 3 & .016 & Gaussian & 100 \\
\hline A. rubribarbus & $-1.03(2.45)$ & -.42 & 14 & .68 & Gaussian & 0 \\
\hline A. sagrei & $-.52(.26)$ & -2.01 & 204 & .046 & Exponential & 50 \\
\hline
\end{tabular}

Note: The results for the GLS analysis closely mirrored those from the nonspatial analysis, except for the relationship for A. ahli, which is significant in the general linear model analysis (table 3). For the GLS models, autocorrelation structure was chosen with the corrected Akaike Information Criterion. One hundred repetitions were performed for each species, with a different random jitter added to localities each time to avoid neighbor distances of 0 . The model with the median slope is presented here. As $P$ values were sensitive to jittering in some cases, the final column gives the number of these 100 models that had a slope with a $P$ value of $<.05$. Elevation was natural log transformed (after adding 0.5 ), and snout-vent length was used as a measure of body size. Significant $(P<.05)$ models are in bold. 


\section{Body Size-Elevation Relationships in the sagrei Clade (Cuba)}

On Cuba, we also found a significant inverse cline in body size with elevation, after accounting for spatial autocorrelation (table A2). We also found significant differences in species' slopes, indicating that intraspecific body size clines varied among species. Our individual species' regressions closely mirrored the nonspatial analysis, with the exception of Anolis $a h l i$. This species slope was significant using a nonspatial model but nonsignificant using GLS $(P=.052)$.

\section{Sensitivity to Random Jittering of Species' Locales}

We randomly jittered localities to avoid distances of 0 separating species collected at the same location. In some cases, $P$ values were sensitive to this procedure, in particular for individual species regressions, although the balance of evidence still indicates significant relationships in these species (tables A2, A3; figs. A2, A3). The exact reasons behind this sensitivity remain elusive, but it likely arises because jittering sometimes induced additional spatial structure, that is, increased the collinearity between interlocality distances and elevation. 

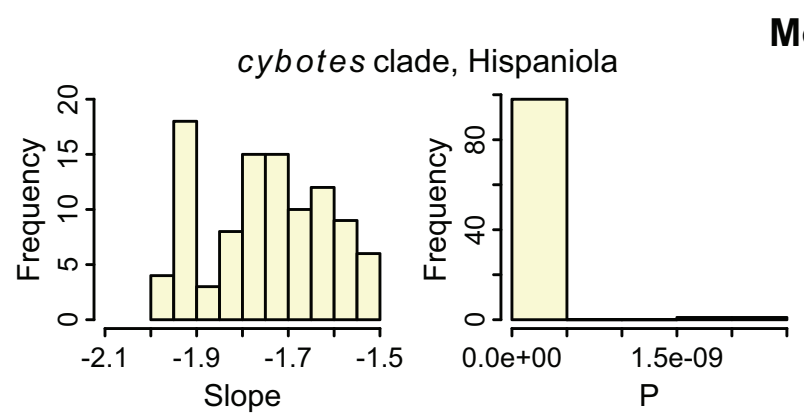

Model 1

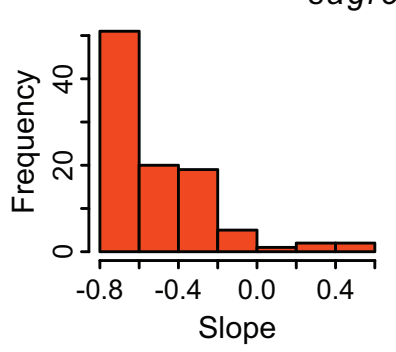

\section{Model 2}
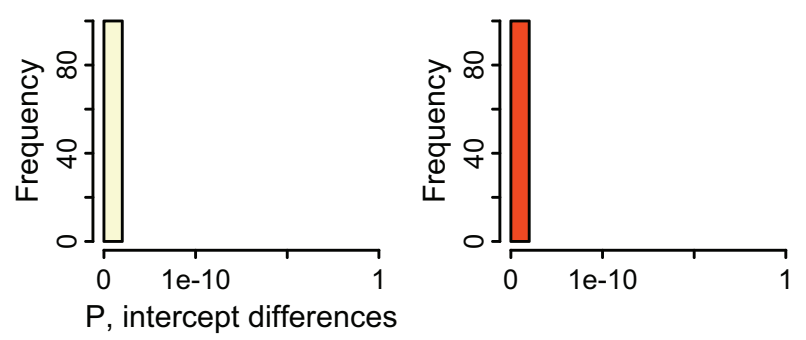

\section{Model 3}
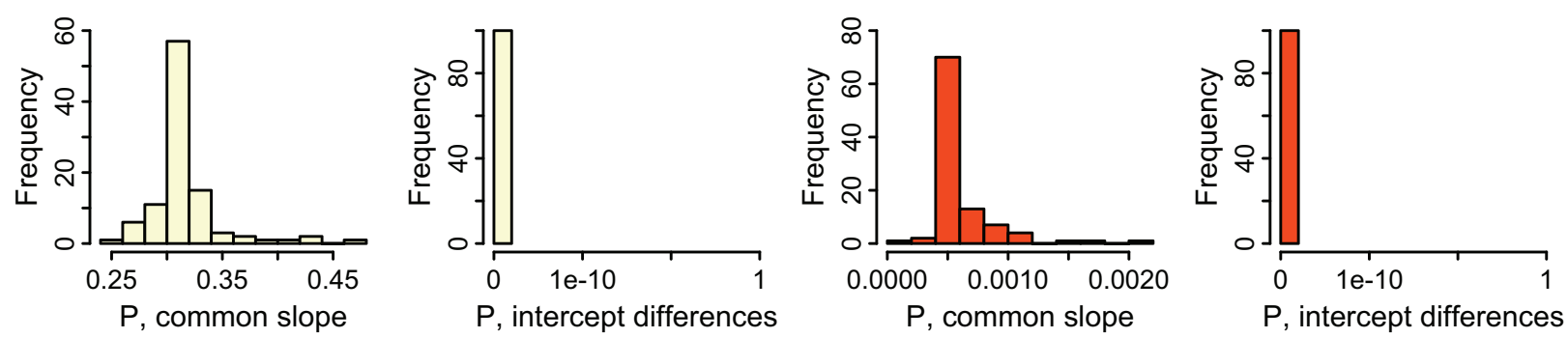

\section{Model 4}
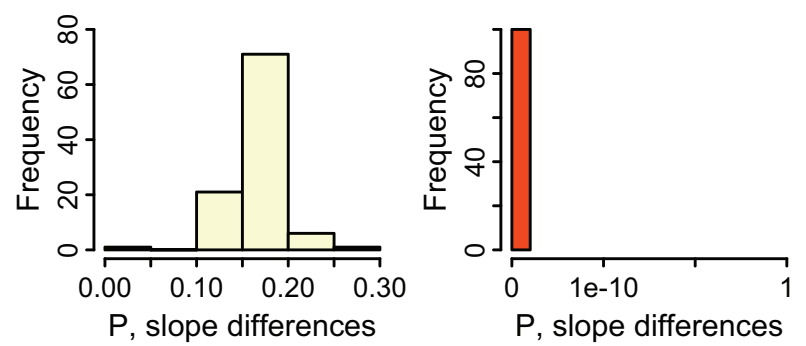

agrei clade, Cuba

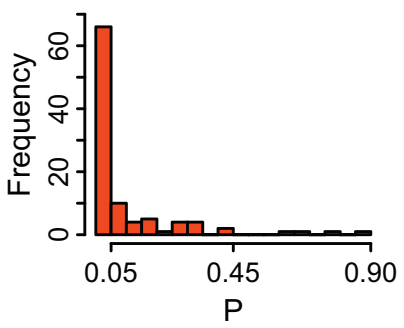


cybotes clade, Hispaniola

\section{A. armouri}
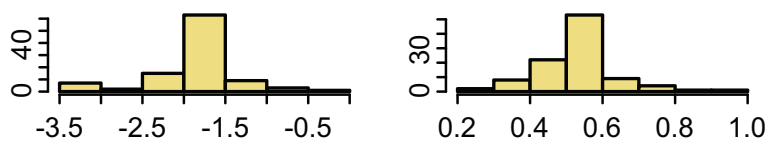

A. cybotes
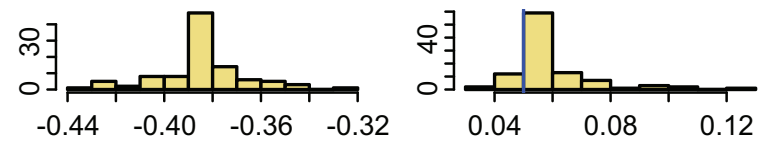

A. longitibialis
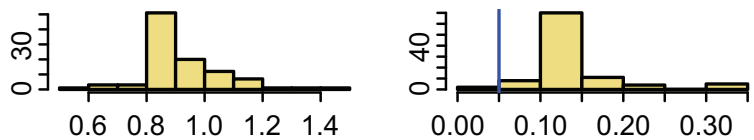

A. marcanoi
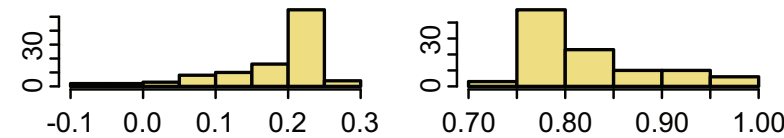

A. shrevei
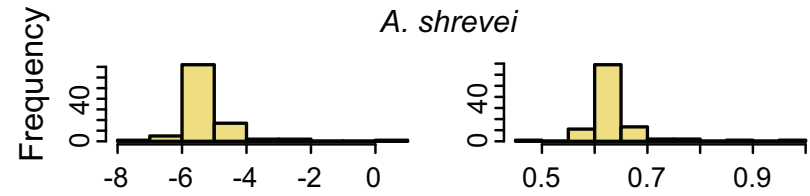

A. strahmi
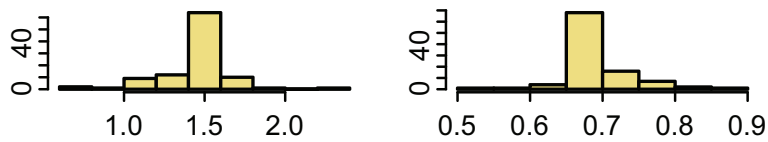

A. whitemani
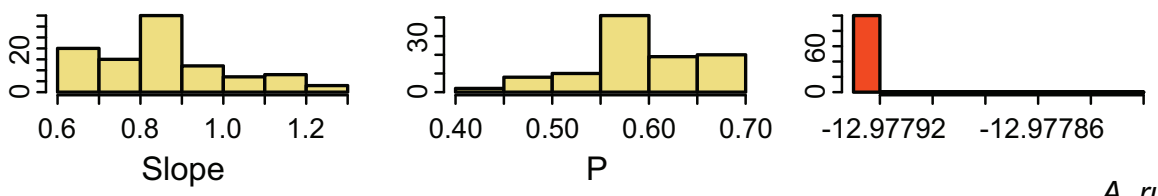

A. quadriocellifer
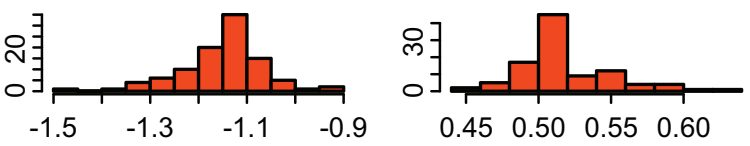

\section{A. rubribarbus}
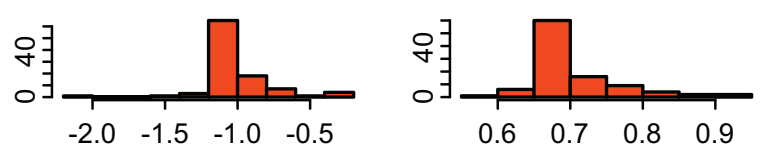

A. sagrei
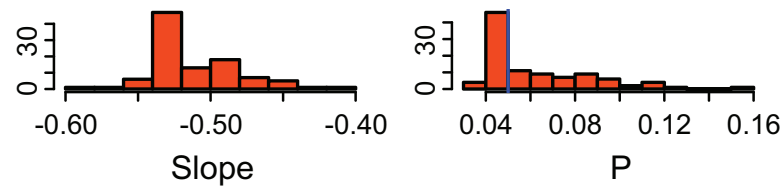

Figure A3: Slope and $P$ values for generalized least squares regressions of snout-vent length on $\ln ($ elevation +0.5$)$ for individual Anolis species, accounting for spatial autocorrelation. Results of 100 regressions for each species are presented, each with a unique small, random jitter added to coordinates to avoid distances of 0 between localities. The cybotes clade (Hispaniola) results are in pale yellow, and the sagrei clade (Cuba) results are in orange-red. 